\title{
Retrospective study of injury rates among children and adults in the Lublin Region of Poland
}

\author{
Renata Domżał-Drzewicka', Agnieszka Saracen², Marcin Rząca', Paweł Węgorowski', \\ Andrzej Stanisławek', Bogdan Piotr Michalak' \\ ${ }^{1}$ Chair of Oncology and Environmental Health, Medical University, Lublin, Poland \\ 2 Department of Nursing, Faculty of Health Sciences and Physical Culture, Kazimierz Pulaski University of Technology and \\ Humanities, Radom, Poland
}

Domżał-Drzewicka R, Saracen A, Rząca M, Węgorowski P, Stanisławek A, Michalak BP. Retrospective study of injury rates among children and adults in the Lublin Region of Poland. Ann Agric Environ Med. 2016; 23(2): 297-303. doi: 10.5604/12321966.1203894

\section{Abstract}

Introduction and objective. In Poland and worldwide, injury rates, as well as accident rates among children and adolescents still remain a social, health and economic problem, despite an attempt to inhibit the growing tendency of this phenomenon. Objective. An attempt to evaluate current trends in injury rates among children and adolescents based on the example of two provinces in the Lublin Region of Poland during the period 2006-2010.

Materials and method. The retrospective study was conducted by the method of examination of documents, using the technique of content analysis. The research material was data from the Emergency Procedures Charts and Medical Emergency Team Response Charts, while the study group were children and adolescents aged from 6 weeks - 19 years, from the counties of Kraśnik and Świdnik in the Lublin Region.

Results. Analysis of the research material showed that during the period examined the number of injuries and accidents in the study group remained on a constant level, with a slight decrease in the number of events at home, accompanied by an increase in the number of road accidents and events which occurred in the school environment and in a public place. It was also found that the spring-autumn season, and in particular the summer months, the age group 7-13 and male gender exerted an effect on the number of injuries and accidents. The analysis did not confirm that injuries related with employment of children and adolescents in agriculture and deaths due to external causes constituted a considerable percentage of the events registered.

Conclusion. Analysis of trends should be a basis for the planning of prophylactic actions and the promotion of safety in all environments in which the study population functions.

\section{Key words}

injury rates, children, adolescents

\section{INTRODUCTION}

In the population of children and adolescents aged 0-19 a high number of accidents, injuries and poisonings are registered annually, which occurred at home, in the nearest surroundings of the place of residence, at school, and on roads $[1,2,3]$. Accidents and not diseases are the main causes of death among children and adolescents aged 1-19, and constitute more than a half of all deaths, whereas in the population aged 15-19 accidents contribute to over $60 \%$ of all deaths. Both in Poland and worldwide, injury rates and accident rates in children and adolescents are a serious social, health and economic problem, despite an attempt to limit the growing tendency of this phenomenon $[1,4,5,6,7,8]$.

Analysis of available reports shows that gender, age, and place of residence are important factors exerting an effect on the number of injuries and accidents. Boys are more frequently at risk of injury or accident than girls. In this group, death rates and the number of hospitalizations are higher, compared to girls. Higher death rates are noted among boys living in rural areas, while urban boys are more frequently hospitalized due to injuries. In addition, in Poland,

Address for correspondence: Renata Domżał-Drzewicka, Chair of Oncology and Environmental Health, Medical University, Staszica 4-6, 20-081 Lublin, Poland E-mail: renatadd@op.p

Received: 04 March 2013; accepted: 03 January 2014 death rates among children due to injuries vary according to area and season of the year. The highest injury and accident rates were observed among children and adolescents aged 7-12 and 13-19 [1, 5, 6, 7, 9].

Data by the UNICEF from 2010 show that more than a half of the child population in Poland were victims to accidents or sustained injury within the last year. Among the most frequent events were: fall from a height $-47.8 \%$, burns $48.4 \%$ and electric shock $-15.6 \%$. At the same time, the data indicate that over $97 \%$ of the children examined were familiar with the emergency telephone numbers that can be dialled in the case of accident, $87 \%$ cross the road only on marked pedestrian crossings, and $88 \%$ fasten belts while travelling by car. Unfortunately, only $65.8 \%$ of children sit in the back seat of a car [10].The results of the presented study are therefore quite alarming.

While analysing the Lublin Macroregion, it should be emphasized that it is characterized by the predominance of agriculture over industry; therefore, the population most often incurred injuries typical for the occupation of a farmer. This group also includes children and adolescents. Each year, approximately 2,000 children are admitted to the wards of the Clinic of Paediatric Surgery and Traumatology at the Medical University in Lublin due to injuries. A high percentage of them are patients who sustained severe injuries threatening serious disability or even death [11]. 
Following the verification of the above-presented data, the questions arise: whether the prophylactic programmes functioning in Poland shape and strengthen the desired attitudes and prophylactic behaviours in the population of children and adolescents, and if these programmes are adjusted to the actually recognized demands in this area?

An increase in the incidence of injuries and accidents observed in Poland, despite the preventive actions undertaken, should result in the development of an all-Polish register of injuries which would allow a comprehensive analysis of these phenomena $[1,9,10]$.

Analysis of risk factors and trends in the area of injury rates among the population of children and adolescents should be the source of information for the assessment of the health situation of this population, planning and evaluation of programmes for prevention, promotion of safety and shaping the national and regional health policy $[3,6,9]$.

The objective of the study was an attempt to evaluate the current trends in injury rates among children and adolescents, based on the example of two counties in the Lublin Region during the period 2006-2010.

\section{MATERIALS AND METHOD}

The study of a retrospective character was conducted during the period 2006-2010 by the method of analysis of documents, using the technique of content analysis.

The research material was data from the Emergency Procedures Charts and Medical Emergency Team Response Charts, while the study group were children and adolescents aged from 6 weeks - 19 years, from the counties of Kraśnik and Świdnik in the Lublin Region.

The following information was registered from the Charts: year of event, date of event (month), victim's age and place of residence, place of event, type and site of injury, or occurrence of death.

The research material obtained was subjected to statistical analysis. The $\mathrm{p}$ values $\mathrm{p}<0.05$ were considered statistically significant.

\section{RESULTS}

During the period 2006-2010, a total of 1,250 (100.00\%) children and adolescents from the counties of Swidnik and Kraśnik sustained injuries, and were covered with care by Medical Emergency Teams. During the period analyzed, a total number of 427 (34.16\%) girls and 823 (65.84\%) boys were the victims of accidents. In the group analyzed, 709 patients were inhabitants of Kraśnik county (56.72\%), while 541 (43.28\%) lived in Świdnik county.

The children and adolescents examined were aged from 6 weeks - 19 years; mean age 11.7; standard deviation 5.55, and from the aspect of age were divided into 5 subgroups according to the individual stage of education. This stage determines specified behaviours and affects the patient's movement and whereabouts, which are closely associated with the type and place of injury.

Analysis of data from the Medical Emergency Team Response Charts showed that during the period 2006-2010 the greatest number of children and adolescents who were victims to accidents were aged 7-13 - 412 (32.96\%), followed by those aged $17-19-320$ (25.60\%), and $14-16-264(21.12 \%)$. The smallest number of injuries were noted among children aged 4-6 - 98 events (7.84\%). In all age groups examined, boys suffered injuries and accidents considerably more often than girls (Tab. 1).

Table 1. Number of injuries in individual years according to victims' age and gender

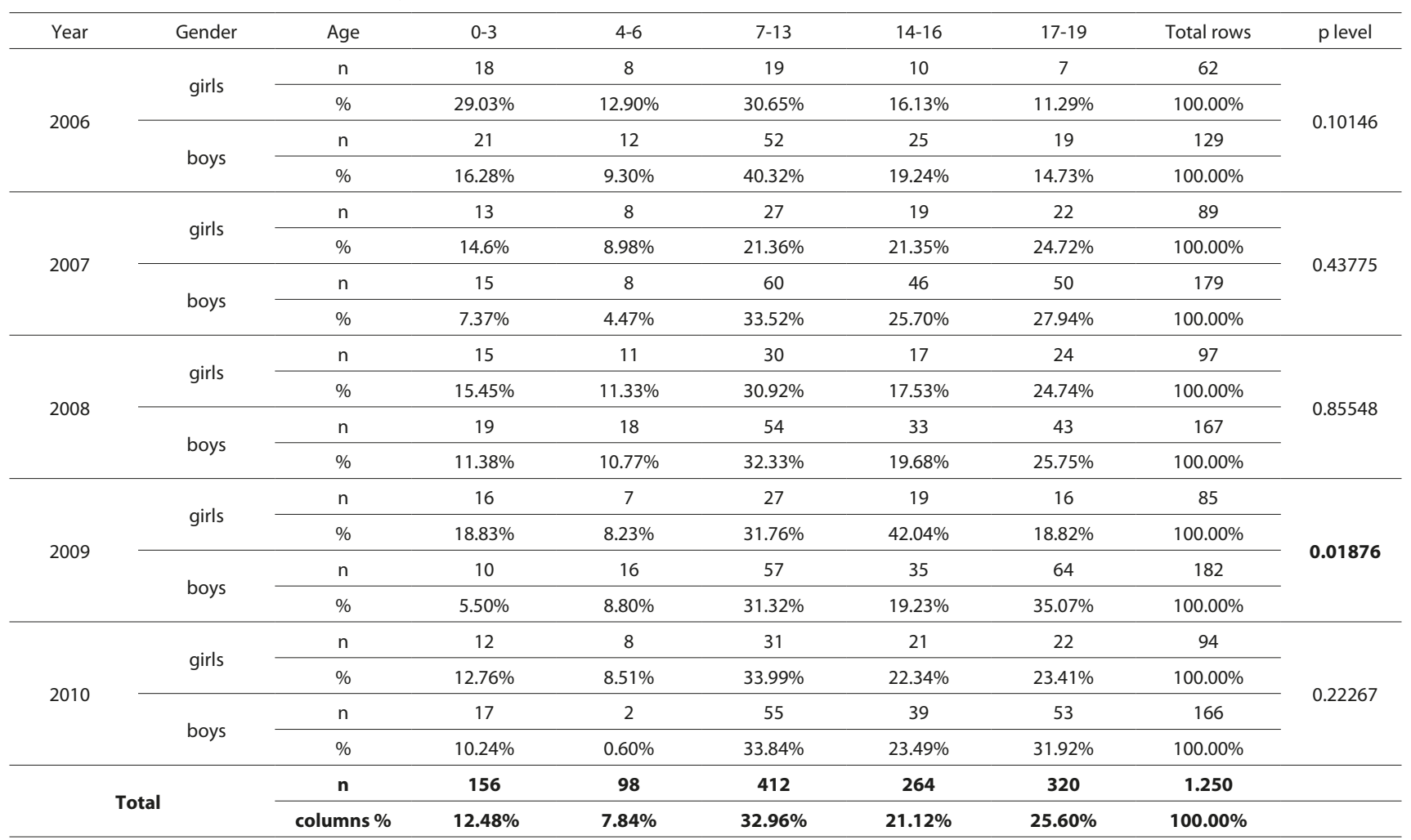


The largest number of injuries among children and adolescents was registered in the spring-autumn season $(\mathrm{n}=1024,81.92 \%)$ with the highest number of injuries and accidents occurring during the summer months (June August, $n=395,31.60 \%$ ). The smallest number of injuries was observed in winter - December-February. Statistical analysis showed a relationship between the winter period and the frequency of injuries sustained by children and adolescents in both provinces, $\mathrm{p}<0.05$. Table 2 presents the frequency of occurrence of injuries and accidents among children and adolescents in individual seasons of the year.

As many as $584(46.71 \%)$ children and adolescents who were victims to accidents came from the rural environment, 565 (45.21\%) from small localities (population up to 50,000), and $101(8.10 \%)$ from towns with over 50,000 inhabitants. The domination of children from the rural areas and small towns among the victims probably results from the specificity of the region which is typically agricultural.

During the period of 5 years, 2006-2010, the most common place where injuries occurred was the family home. In this environment, a total number of 412 (32.96\%) injuries and accidents were registered, mainly among children and adolescents aged $7-13(n=131,31.79 \%), 0-3(n=116,28.15 \%)$, and $14-16(n=63,15.29 \%)$. In the home environment, injuries of the head and upper and lower extremities prevailed. Road accidents occupied the second position, to which 329 (29.52\%) adolescents fell victims who were aged $17-19$ ( $n=131$,
$35.50 \%), 7-13(\mathrm{n}=108,29.26 \%)$, and $14-16(\mathrm{n}=74,20.05 \%)$, and incurred mainly multiple organ injuries. The subsequent environment was school, where 261 (20.88\%) events were registered, mainly among age groups $7-13(n=106,40.61 \%)$, $14-16(n=85,32.56 \%)$, and $17-19(n=53,20.30 \%)$. In this environment dominated injuries concerning the head, and upper and lower extremities. An interesting observation is that children and adolescents suffered injuries most rarely while performing work activities on farms. A total number of only $9(0.72 \%)$ events of this type were noted. No cases of injuries related with performing gainful employment by children and adolescents were observed (Tab. 3, 4).

Statistical analysis showed a statistically significant relationship between place of event and age of the victims, $\mathrm{p}<0.0001$.

While analyzing the site of injury by age it was found that among infants and children under 3 years of age, head injury occurred most frequently $(n=57,36.53 \%)$, followed by burns $(n=35,22.43 \%)$. Among children aged $4-6$, head injuries were also dominant $(n=32,32.65 \%)$, followed by multiple organ injuries $(n=33,33.67 \%)$. Children aged $7-13$ also most often sustained head injuries $(n=119,28.9 \%)$ and multiple organ injuries $(n=109,26.45 \%)$. In addition, in this age group a considerable number of injuries were noted concerning the lower extremities $(n=66,16.01 \%)$, and upper extremities ( $n=63,15.29 \%)$. Among adolescents aged 14-16, multiple organ injuries prevailed $(n=78,29.54 \%)$, followed

Table 2. Frequency of occurrence of injuries and accidents in the group of children and adolescents in individual seasons of the year

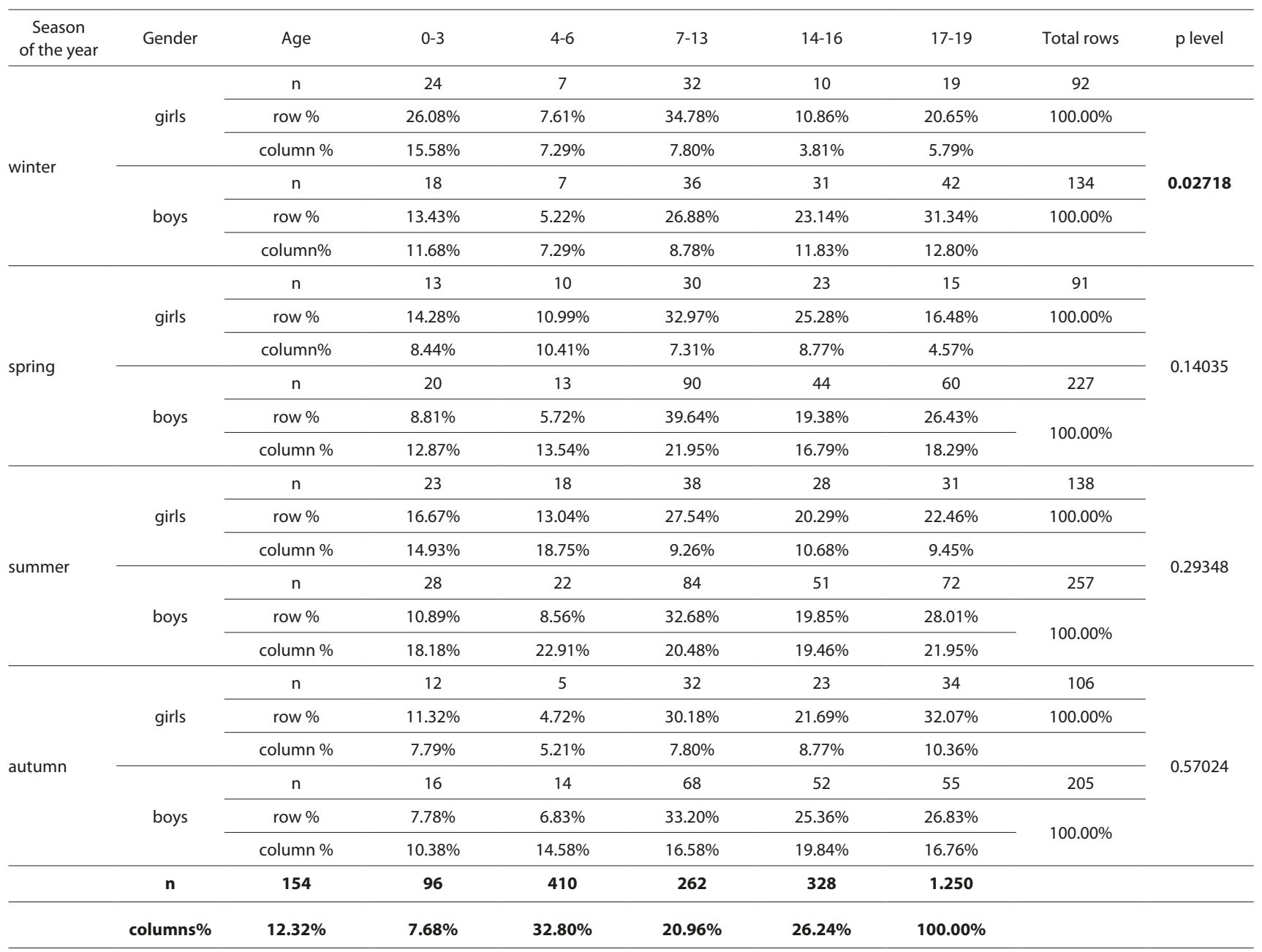


Table 3. Place of event according to age

\begin{tabular}{|c|c|c|c|c|c|c|c|}
\hline \multirow{2}{*}{ Place of event } & & \multicolumn{5}{|c|}{ Age } & \multirow{2}{*}{ Total rows } \\
\hline & & $0-3$ & $4-6$ & $7-13$ & $14-16$ & $17-19$ & \\
\hline \multirow{3}{*}{ home } & $\mathrm{n}$ & 116 & 40 & 131 & 63 & 62 & 412 \\
\hline & row \% & $28.15 \%$ & $9.71 \%$ & $31.79 \%$ & $15.29 \%$ & $15.04 \%$ & $100.00 \%$ \\
\hline & column \% & $74.35 \%$ & $40.81 \%$ & $31.95 \%$ & $23.86 \%$ & $19.37 \%$ & \\
\hline \multirow{2}{*}{ road accident } & $\mathrm{n}$ & 25 & 31 & 108 & 74 & 131 & 369 \\
\hline & column \% & $16.02 \%$ & $31.63 \%$ & $26.21 \%$ & $28.03 \%$ & $40.93 \%$ & \\
\hline \multirow{3}{*}{ school } & $\mathrm{n}$ & 9 & 8 & 106 & 85 & 53 & 261 \\
\hline & row \% & $3.44 \%$ & $3.06 \%$ & $40.61 \%$ & $32.56 \%$ & $20.30 \%$ & $100.00 \%$ \\
\hline & column \% & $5.76 \%$ & $8.16 \%$ & $2572 \%$ & $32.19 \%$ & $16.56 \%$ & \\
\hline \multirow{2}{*}{ public place } & $\mathrm{n}$ & 6 & 18 & 64 & 40 & 71 & 199 \\
\hline & column \% & $3.84 \%$ & $18.36 \%$ & $15.53 \%$ & $15.15 \%$ & $22.18 \%$ & \\
\hline \multirow{3}{*}{ agriculture and other places } & $\mathrm{n}$ & 0 & 1 & 3 & 2 & 3 & 9 \\
\hline & row $\%$ & $0.00 \%$ & $11.11 \%$ & $33.33 \%$ & $22.22 \%$ & $33.33 \%$ & $100.00 \%$ \\
\hline & column \% & $0.00 \%$ & $1.02 \%$ & $0.72 \%$ & $0.75 \%$ & $0.93 \%$ & \\
\hline \multirow{2}{*}{ Total } & $\mathbf{n}$ & 156 & 98 & 412 & 264 & 320 & 1.250 \\
\hline & columns \% & $12.48 \%$ & $7.84 \%$ & $32.96 \%$ & $31.12 \%$ & $25.60 \%$ & $100.00 \%$ \\
\hline
\end{tabular}

$p<0.0001$

Table 4. Type of injury according to place of event

\begin{tabular}{|c|c|c|c|c|c|c|c|}
\hline Type of injury & Place of event & Home & Road accident & School & Public place & $\begin{array}{l}\text { Agriculture and } \\
\text { other places }\end{array}$ & Total rows \\
\hline \multirow{3}{*}{ head injuries } & $\mathrm{n}$ & 192 & 5 & 93 & 50 & 0 & 340 \\
\hline & column $\%$ & $46.60 \%$ & $1.36 \%$ & $35.63 \%$ & $25.13 \%$ & $0.00 \%$ & \\
\hline & row $\%$ & $56.47 \%$ & $1.47 \%$ & $27.35 \%$ & $14.71 \%$ & $0.00 \%$ & $100.00 \%$ \\
\hline \multirow{3}{*}{ injuries of upper extremities } & $\mathrm{n}$ & 65 & 4 & 74 & 40 & 0 & 183 \\
\hline & column $\%$ & $15.78 \%$ & $1.08 \%$ & $28.35 \%$ & $20.10 \%$ & $0.00 \%$ & \\
\hline & row $\%$ & $35.52 \%$ & $2.19 \%$ & $40.44 \%$ & $21.86 \%$ & $0.00 \%$ & $100.00 \%$ \\
\hline \multirow{3}{*}{ injuries of lower extremities } & $\mathrm{n}$ & 56 & 4 & 66 & 42 & 1 & 169 \\
\hline & column $\%$ & $13.59 \%$ & $1.08 \%$ & $25.29 \%$ & $21.11 \%$ & $11.11 \%$ & \\
\hline & row $\%$ & $33.14 \%$ & $2.37 \%$ & $39.05 \%$ & $24.85 \%$ & $0.59 \%$ & $100.00 \%$ \\
\hline \multirow{3}{*}{ injuries of trunk } & $\mathrm{n}$ & 35 & 2 & 21 & 58 & 2 & 118 \\
\hline & column $\%$ & $8.50 \%$ & $0.54 \%$ & $8.05 \%$ & $29.15 \%$ & $22.22 \%$ & \\
\hline & row $\%$ & $29.66 \%$ & $1.69 \%$ & $17.80 \%$ & $49.15 \%$ & $1.69 \%$ & $100.00 \%$ \\
\hline \multirow{3}{*}{ burns } & $n$ & 55 & 0 & 0 & 1 & 0 & 56 \\
\hline & column $\%$ & $13.35 \%$ & $0.00 \%$ & $0.00 \%$ & $0.50 \%$ & $0.00 \%$ & \\
\hline & row $\%$ & $98.21 \%$ & $0.00 \%$ & $0.00 \%$ & $1.79 \%$ & $0.00 \%$ & $100.00 \%$ \\
\hline \multirow{3}{*}{ multiple organ injuries } & $\mathrm{n}$ & 9 & 354 & 7 & 8 & 6 & 384 \\
\hline & column $\%$ & $2.18 \%$ & $95.93 \%$ & $2.68 \%$ & $4.02 \%$ & $66.67 \%$ & \\
\hline & row $\%$ & $2.34 \%$ & $92.19 \%$ & $1.82 \%$ & $2.08 \%$ & $1.56 \%$ & $100.00 \%$ \\
\hline \multirow{2}{*}{ Total } & $n$ & 412 & 369 & 261 & 199 & 9 & 1.250 \\
\hline & column \% & $32.96 \%$ & $29.52 \%$ & $20.88 \%$ & $15.92 \%$ & $0.72 \%$ & $100.00 \%$ \\
\hline
\end{tabular}


by injuries of the head $(\mathrm{n}=63,23.86 \%)$, upper extremities $(n=54,20.45 \%)$, and lower extremities $(n=46,17.42 \%)$. Nearly a half of the adolescents aged 17-19 suffered multiple organ injuries ( $n=135,42.18 \%)$, followed by head injuries $(n=69$, $21.56 \%$ ), and slightly more rarely than the younger age group, injuries of the lower extremities ( $n=45,14.06 \%)$, and upper extremities $(\mathrm{n}=42,13.12 \%)$. Statistical analysis confirmed a strong relationships between the subgroups examined (Tab. 5).

The most frequent consequence of injury among children and adolescents during the period analyzed were multiple organ injuries, which constituted $30.72 \%(n=384)$ of all the body injuries registered. Head injuries occupied the second position ( $n=340,27.20 \%)$, followed by injuries of the upper extremities $(\mathrm{n}=183,14.64 \%)$, and lower extremities $(n=169,13.52 \%)$, as well as injuries of the trunk $(n=118$, 9.44\%) (Tab. 6).

While analyzing the site of injury in individual years the following was observed:

- gradual increase in the number of injuries of the head and lower extremities;

- slight increase in the number of injuries of the upper extremities, compared to 2006; however, there was a decrease in the number of these injuries compared to 2008 ;

- decrease in the number of injuries of the trunk and burns;

- slight increase in the number of multiple organ injuries (Tab. 6).

Injuries most often occurred in the locality where the victims originated $(n=548,43.84 \%)$. In $27.12 \%(n=339)$ of cases, the place of residence was equivalent to the place of event, which evidenced that the event occurred at a patient's home or within the household. In the remaining cases $(n=363,29.04 \%)$, the place of event was different from the above-mentioned. Statistical analysis showed a statistically significant relationship between the place of residence and place of event or accident $(\mathrm{p}<0.0134)$.

It was observed that during the period analyzed the number of injuries and accidents among children and adolescents maintained itself on a constant level.

Data from analysis of the documentation showed that during the period $2006-2010,9$ patients (0.72\%) aged 0-19 died as a result of body injuries.

\section{DISCUSSION}

The analysis performed showed that in the group of children and adolescents, injuries still constitute a serious health, social and economic problem, despite the implementation of certain prophylactic actions [9, 12, 13, 14, 15]. It was observed that during the period analyzed the number of registered injuries remained on a constant level. Reports by other researchers who analyzed trends in injury rates and accident rates among the population of Polish children and adolescents, as well as reports by State institutions, confirm that the level of registered injuries and accidents remains constant, with an indication towards a growing tendency $[5,13,14]$.

Differences are observed primarily with respect to the frequency of occurrence of specific types of injuries, as well as the place of their occurrence and the age of the victims. The largest number of injuries was noted in the age group $7-16$, with the emphasis placed at the age between 7-13, i.e. the time of attending elementary school. This trend is confirmed by analysis of the results of performance of the

Table 5. Site of injury in individual age groups

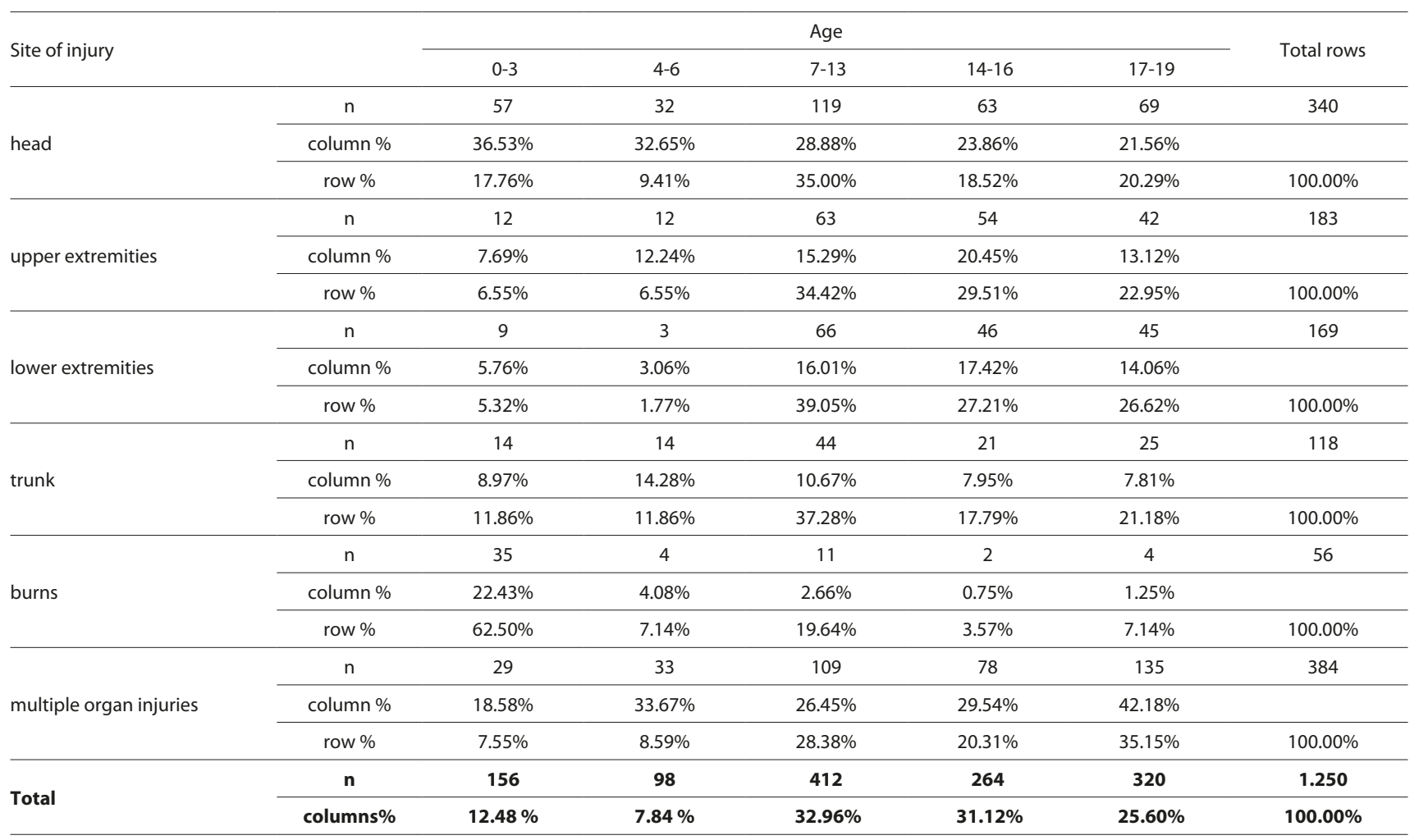


Table 6. Site of injury according to year of event

\begin{tabular}{|c|c|c|c|c|c|c|c|}
\hline \multirow{2}{*}{ Site of injury } & & \multicolumn{5}{|c|}{ Year of event } & \multirow{2}{*}{ Total rows } \\
\hline & & 2006 & 2007 & 2008 & 2009 & 2010 & \\
\hline \multirow{3}{*}{ head } & $\mathrm{n}$ & 57 & 67 & 66 & 63 & 87 & 340 \\
\hline & row $\%$ & $16.76 \%$ & $19.70 \%$ & $19.41 \%$ & $18.52 \%$ & $25.58 \%$ & $100.00 \%$ \\
\hline & column $\%$ & $29.84 \%$ & $25.00 \%$ & $25.00 \%$ & $23.59 \%$ & $33.46 \%$ & \\
\hline \multirow{3}{*}{ upper extremities } & $\mathrm{n}$ & 24 & 28 & 55 & 41 & 35 & 183 \\
\hline & row $\%$ & $13.11 \%$ & $15.30 \%$ & $30.05 \%$ & $22.40 \%$ & $19.12 \%$ & $100.00 \%$ \\
\hline & column $\%$ & $12.56 \%$ & $10.44 \%$ & $20.83 \%$ & $15.35 \%$ & $13.46 \%$ & \\
\hline \multirow{3}{*}{ lower extremities } & $\mathrm{n}$ & 27 & 30 & 36 & 34 & 42 & 169 \\
\hline & row $\%$ & $15.97 \%$ & $17.75 \%$ & $21.30 \%$ & $20.11 \%$ & $24.85 \%$ & $100.00 \%$ \\
\hline & column \% & $14.13 \%$ & $11.19 \%$ & $13.63 \%$ & $12.73 \%$ & $16.15 \%$ & \\
\hline \multirow{2}{*}{ trunk } & $\mathrm{n}$ & 26 & 27 & 21 & 27 & 17 & 118 \\
\hline & column $\%$ & $13.61 \%$ & $10.07 \%$ & $7.95 \%$ & $10.11 \%$ & $6.53 \%$ & \\
\hline \multirow{3}{*}{ burns } & $\mathrm{n}$ & 11 & 17 & 9 & 11 & 8 & 56 \\
\hline & row $\%$ & $19.64 \%$ & $30.35 \%$ & $16.07 \%$ & $19.64 \%$ & $14.28 \%$ & $100.00 \%$ \\
\hline & column \% & $5.75 \%$ & $6.34 \%$ & $3.40 \%$ & $4.11 \%$ & $3.07 \%$ & \\
\hline \multirow{3}{*}{ multiple organ injuries } & $\mathrm{n}$ & 46 & 99 & 77 & 91 & 71 & 384 \\
\hline & row $\%$ & $11.97 \%$ & $25.78 \%$ & $20.05 \%$ & $23.69 \%$ & $18.48 \%$ & $100.00 \%$ \\
\hline & column \% & $24.08 \%$ & $36.94 \%$ & $29.16 \%$ & $34.08 \%$ & $27.30 \%$ & \\
\hline \multirow{2}{*}{ Total } & $\mathbf{n}$ & 191 & 268 & 264 & 267 & 260 & 1.250 \\
\hline & columns \% & $15.28 \%$ & $21.44 \%$ & $21.12 \%$ & $21.36 \%$ & $20.80 \%$ & $100.00 \%$ \\
\hline
\end{tabular}

$\mathrm{p}<0.006$

programme concerning the improvement of health care of children and adolescents in the environment of their life and education, monitored by the Lublin Centre for Public Health during the period 2003-2007 [6, 11].

In the group examined, nearly a half of the injuries concerned children and adolescents living in the rural areas. With respect to the results of own studies, this may be associated with the specificity of the investigated regionagricultural counties. While analyzing the reports by other researchers and reports by government institutions, it may be presumed that the place of residence is significantly related with the number of injuries and accidents registered in a given area. A larger number of injuries and accidents are observed among children and adolescents from the rural areas $[16,17$, 18], with the injuries occurring mostly during the springautumn season, and with the largest number registered in the summer months. A similar seasonal character of injuries is observed in other countries of the European Union [13, 19, 20]. However, Polish data show a considerably higher incidence of injuries, accidents and deaths due to injuries among the population of children and adolescents, compared to other countries of the EU $[5,8]$. This fact must be taken into consideration while shaping social and health policy in Poland. This trend clearly shows the necessity for monitoring these determinants and developing prophylactic programmes which should be adjusted to the local needs and specificity of rural areas.

The most frequent place in which injuries were incurred was the home environment, and site of road accidents. These observations are consistent with the reports by other researchers [16]. During the period analyzed, deaths as a result of an unintentional external event constituted less than $1 \%$ of cases. It is noteworthy that the percentage of injuries related with the engagement of children and adolescents in work on farms was low. If this trend maintains itself, it may evidence an increasingly greater awareness of parents and caregivers in the area of protection of the health and life of their children, and effectiveness of prophylactic actions undertaken. Analysis of the relevant literature does not confirm any considerable decrease in the scope of engagement of children and adolescents in work on farms $[13,18,21,22,23]$.

An upward tendency is noted with respect to multiple organ injuries and head injuries. These injury rates are dominant during the first years of life of children, and during the time of obligatory school attendance, constituting the primary cause of death and disability [16]. The period between the age $0-3$ years of life, is also characterized by a large number of injuries occurring as a result of burns. This trend is also observed, although with a smaller intensity, in the countries of Western Europe and the USA, where observations are carried out of injury and accident rates among children and adolescents, and prophylactic programmes are developed based on examination of the situation $[24,25]$.

The data presented earlier provide numerous conditions for formulating preventive recommendations. However, one should mention that the accurate, reliable diagnosis of the initial situation which provides a basis for the implication of preventive recommendations, should rely on long-term observation and the measurement of analysed variables. Todate, this is lacking in Poland and this lack of a registration system and analysis of causes of injuries in the examined population, hampers taking accurate, long-term preventive operations and contributes to the ineffective use of financial resources in the system of the health care [25]. Yet, analysis of the research material and the literature on the subject points 
to the primary source of the traumatism: ill-considered, risky behaviour of the aggrieved parties and their carers.

While regarding the reason for the existence of the traumatism, it is possible to attempt to show the basic directions for its prevention. Their purpose should be to change the risky, individual behaviours and extending the responsibility for own health and life, and the lives of others, as well as reducing the exposure to risk factors in the living environment of children and adolescents (home, school, etc.). Polish health policy must be directed at the promotion of health, the prevention of accidents, and using all available resources for achieving the above aims.

In Poland, preventive action adapted for the specificity of the area and environment where injuries and accidents occur must be prioritised, with the full participation of all those concerned, i.e. local self-government, staff of the of health care system, including doctors, nurses and midwives, as well as specialists from public health and education. A model must be implemented in Poland of accident prevention among children and teenagers, which is both elastic and internally cohesive with the health policy of the country, based on observation of local, domestic and international trends.

\section{CONCLUSIONS}

To sum up, analysis of the material collected during the period 2006-2010 indicated the following trends:

1. a constant number of injuries and accidents in the group examined;

2. a slight decrease in the number of events at home, although this place still remains one of the most common where injuries occur;

3. an increase in the number of road accidents, injuries in the school environment and in public places;

4. it was confirmed that boys are more frequently victims to injuries and accidents than girls;

5. it was confirmed that in the age group 7-13 the largest number of external events of an unintentional character were noted;

6. it was not confirmed that injuries related with the engagement of children and adolescents in work on farms, and deaths due to external causes constitute a considerable percentage of all the events registered;

7. the most frequent types of injuries were multiple organ and head injuries, which occurred at home or in the vicinity, as well as injuries as a result of a road accident;

8. injuries occurred mostly during the spring-autumn season, with the largest number registered in the summer months;

9. these deliberations should be grounds for planning preventive action and safety promotion in all environments in which the examined population functions, and should become a basis for discussion on a Polish model for accident prevention among children and adolescents.

\section{REFERENCES}

1. Goryński P, Wojtyniak B, Kuszewski K. The monitoring of the projected outcome of implementing the National Health Programme. The National Institute of Hygiene, Warsaw 2004.

2. The National Health Programme for the years 2007-2015 adopted by Resolution No. 90/2007 of the Council of Ministers of 15 May 2007 on the National Health Programme for the years 2007-2015.

3. Malinowska-Cieślik M, Czupryna A. Accidents and injuries incurred by school-age children in Poland. Zdr Publ. 2002; 112 (4): 1-5.

4. Peden M. World report on child injury prevention appeals to "Keep Kids Safe”. In Prev. 2008; 14: 413-414.

5. http://www.stat.gov.pl/cps/rde/xbcr/gus/l_podst_inf_o_syt_ demograficznej_2011.pdf (access: 2013.02.16).

6. Książek P, Herda J: Accidents, injuries and intoxications in population of children and adolescents. Zdr Publ. 2008; 118(4): 398-402.

7. Szymborski J. (ed.): Public Health and Population Policy. Rządowa Rada Ludnościowa, Warszawa 2012.

8. MacKay Morag J, Vincenten AJ. Leadership, infrastructure and capacity to support child injury prevention: can these concepts help explain differences in injury mortality rankings between 18 countries in Europe? Eur J Public Health 2010; 22 (1): 66-71.

9. Kułaga Z, Litwin M, Wójcik P, Winecka-Jakubowska A, Grajda A, Gurzkowska B, et al. Current trends in external causes of death of children and adolescents in Poland. Probl Hig Epidemiol. 2009; 90(3): $332-341$.

10. http://www.unicef.pl/Co-robimy/Aktualnosci/UNICEF-obezpieczenstwie-dzieci-w-Polsce (access: 2012.03.23).

11. http://www.dsk.lublin.pl/index.php?id=73 (access: 2012.03.23).

12. http://ww w.rynekzdrowia.pl/Ualugi-medyczne/Chirurdzyprzestrzegaja-Urazy-sa-naj... (access: 2012.06.22).

13. Sosnowska S, Kostka T. Incidence and nature of farm-related injuries among children aged 6-15 during a 10 year period in one region in Poland. Cent Eur J Public Health 2007; 15(1): 33-7.

14. Oblacińka A, Wojnarowska B. Subjective health, life satisfaction and health behaviour of students of secondary schools in Poland in the context of psychosocial and economic factors. A study report. The Mother and Child Institute, the School Medicine Institute, Warsaw 2006.

15. Armour -Marschall J, Wolfe I, Richardson E, Karanikolos M, McKee M. Childhood deaths from injuries: trends and inequalities in Europe. Eur J Public Health 2011; 22(1): 61-65.

16. MacKay M, Vincenten J. Child Safety Report Card 2007- Poland. Amsterdam: European Child Safety Aliance, Eurosafe 2007.

17. Lachowski S. Accidents rate among children. Zdr Publ. 2009; 119(4): 451-454.

18. Lachowski S. Engagement of children in agricultural work activities scale and consequences of the phenomenon. Ann Agric Environ Med. 2009; 16: 129-135.

19. Foltran F, Avossa F, Fedeli U, Baldi I, Spolaore P, Gregori D. Seasonal variations in injury rates in children: evidence from a 10 -year study in the Veneto Region, Italy. Int J Inj Contr Saf Promat. 2012, May 28.

20. Wysocka M. W lecie rośnie liczba wypadków z udziałem dzieci. (In summer the number of accidents to which children are victims increases) Puls Med. 2004; 17: 88.

21. Lewandowski B, Szymańska J. Agriculture-related severe craniofacial injuries in rural children and adolescents. Ann Agric Environ Med. 2008; 15(1): 59-62.

22. Yates J, Mckay M, Nicholson AJ: Patterns of scald injuries in childrenhas anything changed? Ir Med J. 2011; 104(9): 263-5.

23. Gomez de Segura Nieva JL, Boncompte MM, Sucunza AE, Louis CL, Segui-Gomez M, Otano TB. Comparison of mortality due to severe multiple trauma in two comprehensive models of emergency care: Atlantic Pyrenees (France) and Navarra (Spain). J Emerg Med. 2009 Aug: 37(2): 189-200.

24. Ashida S, Heaney CA, Kmet JM, Wilkins JR 3rd.: Using protection motivation theory and formative research to guide an injury prevention intervention: increasing adherence to the North American Guidelines for Children's Agricultural Tasks. Health Promot Pract. 2011 May;12(3):396-405.

25. Sharma M, Lahoti BK, Khandelwal G, Mathur RK, Sharma SS, Laddha A: Epidemiological trends of pediatric trauma: A single-center study of 791 patients. J Indian Assoc Pediatr Surg. 2011 Jul; 16 (3):88-92. 